\title{
Expressive Superorganisms
}

\author{
MARANTHA DAWKINS \\ Carnegie Mellon University
}

This paper outlines a symbiotic mode and model for design, drawn within discussions of expressivity, subjectivity, and multiscalarity. The figure of the superorganism represents an ecological being, open to fluid communication and unbound from normative frameworks intent upon systematizing technocratic exchanges of human concern. The superorganism extends and enriches notions of embodiment toward the communal coproduction of animate ecological territories.

\section{EXPRESSIVITY}

Contexts are "thickenings of matter at different scales;"1 distributions of expressions without clean edges. Thinking about the built world this way releases morphological norms from their privileged positions and provides the viscous co ntext of communication between objects like wine glasses and opera singers, which in specific moments, at specific pitches, express explosions together. ${ }^{2}$ This is an argument for closeness, intensity, and emergence over discreteness and clean causality.

To reconfigure how things hold themselves together is not a form of explosive nihilism but an exercise in defamiliarization that works in service of the accommodation of other species and things, creating looser definitions more open to change and reinterpretation. This exercise enables the design of more meaningful connections in both material and theoretical contexts of imposed division. Expressivity frames life as an intensive and inclusive field from which vivid connections can be made.

Expressivity belongs to rock strata, to bees, and to acts of love. ${ }^{3}$ Deleuze and Guattari discuss expression in A Thousand Plateaus as autonomous, alloplastic distributions which are "able to bring about modifications in the external world,"4 whether they originate organically or inorganically. The expressive body is not just a thing but "a coding, a dynamic structuration, a dynamic formation."5 During Pleistocene glaciations, pressurized sheets of glacial ice refracting deep blue light advanced through great plains, damming rivers, creating lakes, leaving boulders behind and deepening channels to form hummocks, mountains, and valleys. They shaped conditions for networks of forests, animal territories, and millions of years later for human accretion at river edges as sites of colonization and industry, of smoke and soot that would coat buildings for hundreds of years; signaling progress, alienation, civilization, and transforming landscapes into Cities of Dreadful Night ${ }^{6}$ that would later become carbon dioxide domes entrapping particulate matter, inciting asthma in young residents and disturbing rhizospheric nutrient transfer. Expressivity is both a declaration of identity and a communication with environment that selects and composes boundaries and arrangements. Expression is used to alter fields of intensities to create superorganismic entities which emerge and dissolve as they navigate the world.

The superorganism is related to the theories of ecological niche and the interdependent, open system of general systems theory. It is augmented by a fluidity which transforms conditions of identity, action, and response into conditions of embodiment, communication, form, and relation. Expressivity frees the superorganism from the inertia of being primarily a container for animate organisms by focusing on them as things with metabolisms, behaviors, properties, and sentience all their own: irreducible selves that are critically permeable and highly unstable.

Superorganisms complicate notions of individuality and interiority by herding shapes and figures into ecological organizations that are accommodating, multiple, unfinished, and permanently partial. ${ }^{7}$ They thicken and focus. Rather than relying on known classifications to structure the world, the effects of communicative interaction instigate modes of partnership, dynamic difference, and change. Expressions are acts of attunement ${ }^{8}$ and adaptation, where the spaces between objects can reveal a duplicity, or multiplicity, inherent to intimacy. Deleuze and Guattari call on this in their description of the double-figure of the orchid and the wasp, where an orchid will take on characteristics of female wasps to engage male wasps in a courtship. As the orchid engages in a becomingwasp, the wasp engages in a becoming-orchid: it becomes the orchid's reproductive organ, transferring pollen from flower to flower. ${ }^{9}$ This is not simply an act of mimicry, but of true incorporation through trans-species expression. Expressivity calls for a different understanding of being; sensitivity to the intimacy between things represents a critical ontological shift wherein subjectivity is constructed around sensibility.

\section{NOT KNOWING}

Attunement makes available the position of not knowing. This position of humility, openness, and unfamiliarity uncovers subjective and ultimately ecological effects hidden by normative practice. Not-knowable chasms are everywhere, between and inside objects, in ourselves: the chasmic space is built into the formation of our subjectivities. The irony of 


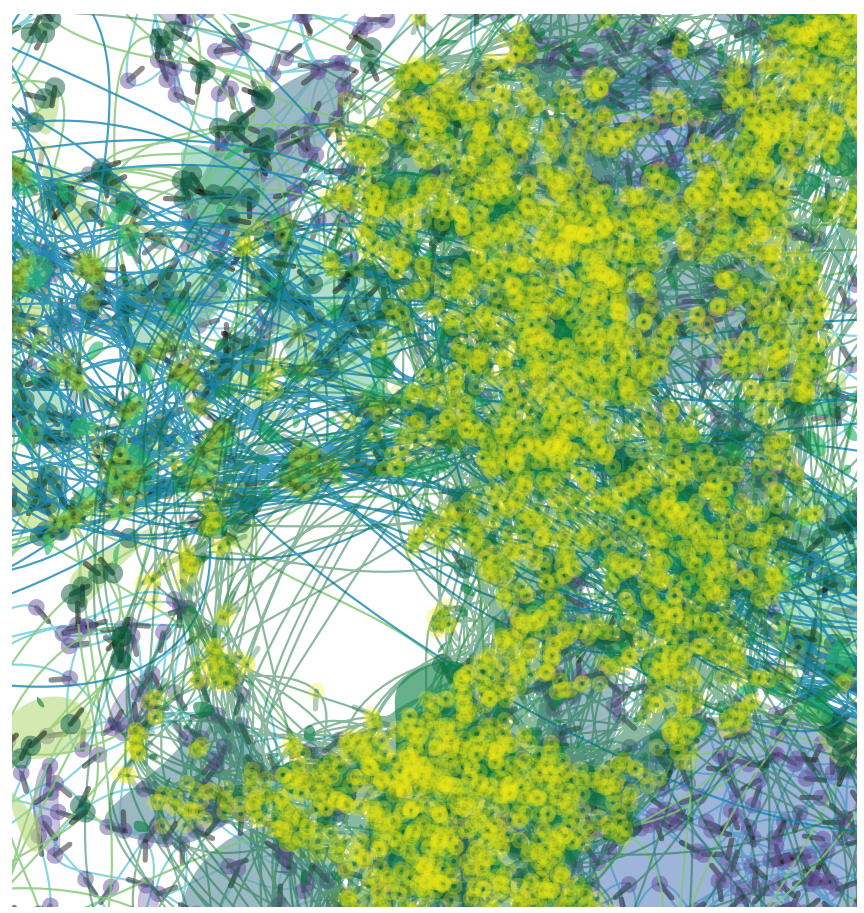

Figure 1. Agent Field.

not knowing oneself reveals contradictions that reverberate outward and leave every whole unresolved ${ }^{10}$ - stripped of its illusions of exclusivity and permanence. Lacanian notknowing is fundamental to his construction of the subject, and takes the form of a gap between the self and the object of the self. Lacan conceptualizes this as embodied in another object known as the petit objet $a$, often considered the object of desire, understood more expansively as the absence of knowledge of the self which performs a pathological selfhaunting, a function of the desiring-machine which produces new material effects, holes, and vaguenesses.

This pathological self-haunting is a direct result of embodiment (of not just being, but being a thing). In The Visible and Invisible, Maurice Merlau-Ponty argues that the divergence "between the sentient and the sensible" is constitutive of the subject. Merlau-Ponty suggests that the realization that the world is not simply an object "does not mean that there was a fusion or coinciding of me with it: on the contrary, this occurs because a sort of dehiscence opens my body in two, and because between my body looked at and my body looking, my body touched and my body touching, there is overlapping or encroachment, so that we may say that the things pass into us, as well as we into the things." ${ }^{11}$ Understanding subjectivity this way removes it from realms of Western dualist abstraction and puts it in touch with the material world surrounding it.

Biologists might describe this dehiscence in terms of genotype and phenotype, wherein the relationship between inherited genetic information and environmental factors determines an organism's morphology, development, and behavior. The genotype-phenotype relationship has been expanded to make space for immense plasticity in both. As an analogical mode of thinking in design, the genotype and phenotype refer to typology and contextual response. This puts a great deal of pressure on the definition of the type and questions of contextual representation, which are often exercises in discovery through systematization rather than open exploration. The concept of horizontal gene transfer moves beyond bidirectional exchange and describes transference of genetic material between organisms through relationships other than that of parent to offspring. In her 1970 work The Origin of Eukaryotic Cells, Dr. Lynn Margulis described the significance of symbiotic events on the complexity of many forms of life. For example, chloroplasts, which are secondary bodies in algae and plant cells that carry out photosynthesis, are theorized to have evolved from symbiotic cyanobacteria. The DNA of chloroplasts was discovered to be different from the DNA of their hosts, provoking the theory that nucleated cells are more like symbiotic communities than single individuals. ${ }^{12}$ Making space for a symbiotic model, as both a subjective and material turn, has the potential to inform an ecologically haunted design practice more open to passages between and within.

Though diminished through much of the progression of the discipline during the 20th century, Frederick Clement's first book on ecology in 1905, Research Methods in Ecology, explored multiscalar communities of organisms as forming complex organisms themselves. These superorganisms possessed their own functions, structures, and developments that destabilized the theoretical balance between the whole and the sum of its parts. ${ }^{13}$ The looseness that was lost through the development of bunked concepts like the equilibrium paradigm is critical to the observation, representation, and formation of matter. Ecological expression is a question of cooperation within consantly shifting thresholds rather than an exercise in balancing equations.

Shaping and thinking the superorganism is an exercise in creating affinity, not through a notion of universal interoperability empowered by concepts like the Internet of Things but through the delineation of a more critical design imaginary which is able to leverage tools of division, waste, isolation, and specialization towards affinitical embodiments that operate through, and take advantage of, the chasms of not knowing in an experimental spirit of partiality, inseparability, and solidarity.

\section{MULTISCALAR EMBODIMENT}

Considering flux and instability as inherent to the superorganism creates ambiguities between interiority and exteriority; and complicates the notions of parts, wholes, and borders. The simultaneous divergence and coupling of superorganisms represents a different way of thinking about embodiment in an ecologically entangled world. Issues of threshold are central 

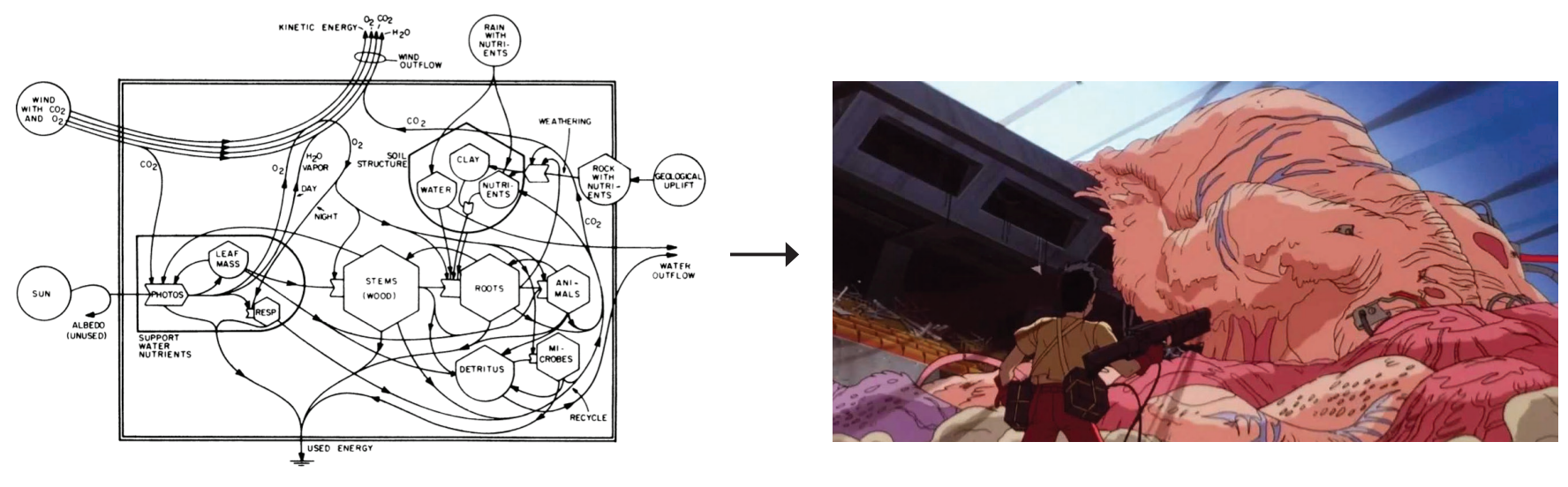

Figure 2. Odum to Akira (Reproduced by permission from Energy Systems and Environmental Education; Elizabeth C. Odum and Howard T. Odum. Akira, 1988).

to the design of the built environment, whether one is working with walls, stream edges, sonic gradients, or particulate matter. But rather than ending at its fingers, the superorganism's boundaries thicken, creating tendrils from a stomach to the origin of a coffee bean; wired connections to power lines; and memories stored in the Cloud. Partiality throws into focus an interscalar relativity that unlocks new media of expression and enables the understanding of emergent phenomena as ecological conversations developing material, informational, subjective, and affective connections to a superorganism's surroundings and community. Attempts to understand these expressions often amount to rather exacting accounts of input and output, which scale organismic metabolism up to the ecosystem to shed light on connectivity and energetic transfer, but which often leave out issues of form, intention, expression, contingency, and directionality. On the left of figure 2 is an example of HT Odum's ecological diagrams, tracing a terrestrial ecosystem in his symbolic language 'emergese' to create an energy circuit with sources, tanks, sinks, interactions, consumers, producers, switches, receivers, amplifiers, and transactions. I argue that this view should be enhanced with the viscerality, projective capacity, reflection, sensitivity, and personality of $A$ kira's grotesque and poignant treatment of Tetsuo (right), a young boy living in Neo Tokyo who is swallowed up by his body's power after being exposed to secret military experimentation in the context of nuclear war, of a societal split along fault lines of spirituality and technology, growing anti-government protests, and the angst of building and maintaining interpersonal relationships as a teenager.

In a world where we are flattened into one-dimensional ${ }^{14,}$ ${ }^{15}$ grey goo, ${ }^{16}$ we are surrounded by and embedded within expressions that are becoming increasingly invasive, and increasingly difficult to detect. It is impossible to isolate these expressions into discrete elements using the techniques presented by emergy diagrams in landscapes that have become hybrid sites of exchange. Slow and heavy organizations are defined by technologies like planning documents and sewer infrastructure; flexible, responsive, and networked technologies have advanced most revealingly to increase the efficiency of war. The concurrently light and ubiquitous technological augmentation of systemic urban space reveals a transparency society ${ }^{17}$ that collects and organizes data in the service of a constant maintainence of neoliberal cartographies and disciplinary governmentalities - human systems developed for control and dividuation in a frictionless and data-rich world.

Embodied expressions are a counterpoint to the control network of the transparency society. Their alignment with an ecological epistemology decenters narrow human concepts and brain-based intelligence in favor of multiscalar behavior, coupled and distributed intelligence, and the design of voluminous connections rather than paths toward exclusive goal completion.

\section{SUBJECTIVE ECOLOGIES}

In the context of a hazy perceptual, technological, and biological space of interactions, design must flex its dynamic and symbiotic potential beyond superficial green applique and toothless biomimicry. In an attempt to explore the intensive properties of the media of design, many practitioners are turning to material behavior. Advances in material and computer science have enabled recent progress on active materials - from synthetic biology, to nanoscale structures, to modular self-assembling robots. In Active Matter, designer Skylar Tibbits from MIT's Active Matter Lab discusses how we can redefine our relationships with matter by embedding historically digital concepts like "logic, reprogrammability, reconfiguration, error correction, and assembly/disassembly" into the physical world, and historically natural properties like "growth, repair, mutation, and replication" into the synthetic world; positing that "these principles are now fundamentally available to read/ write within matter itself." ${ }^{18}$ Outside of these neatly bound bio-synthetic hybridizations, however, lie sets of expressions that are less dependable, but far more open and far more expressive. Through the lens of materiality, for example, wood possesses anisotropic and information-rich 


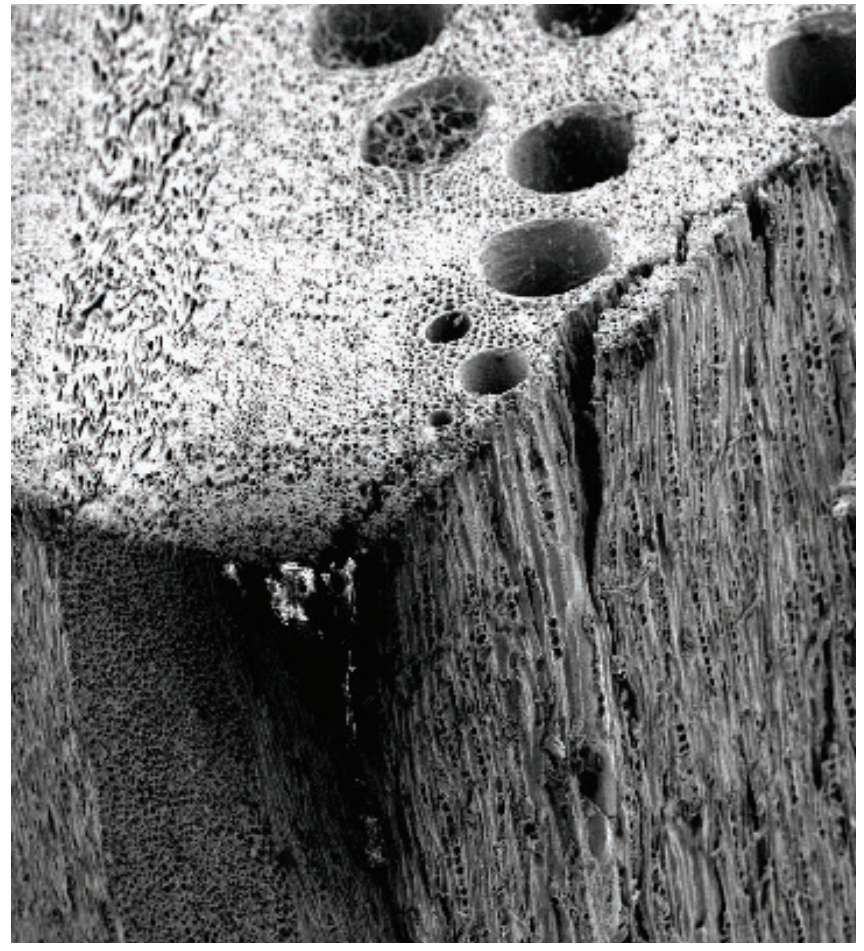

Figure 3. SEM image of Oak pores. (Mckdandy, distributed under a CC-BY 2.5 license).

characteristics that are lost in fabrication methods agnostic to its material capabilities. But the act of isolating wood from its tree extracts it from expansive mychorrhizal networks where fungi exchange phosphorus and nitrogen acquired from the soil with carbon-rich sugars produced by the tree during photosynthesis; and severs the nutrient, genetic, and hormonal networks with surrounding trees which can communicate warnings to each other about imminent attacks, as well as balance and distribute resources. ${ }^{19}$

The capacity of the living tree creates broader potential for design. In 1978, Katherine Carter Ewel and HT Odum introduced the use of Floridian cypress swamps for nutrient removal and wastewater recycling. ${ }^{20}$ Their research illustrated the power of working with local ecologies to relieve pressure on overburdened infrastructures, and inspired many designers and urbanists to consider issues of ecological context. But though this work engages ecological processes of exchange, it makes use of plant life in a way that relegates it to the status of an worker in a Taylorist machine, valuable by way of a narrow understanding of utility rather than expressivity, creativity, and intelligence. Using behavior and expression as a framework for exploration and study has led to revelatory discoveries about plant life which extend vibrancy to previously neutral concepts of environmental context. In her work, biological scientist Dr. Monica Gagliano experimentally tests "the cognitive abilities of plants, including perception, learning processes, memory and consciousness." ${ }^{21}$ According to current research, the view that plants are preprogrammed to grow the way they do is no longer tenable: plants live in a subjective world where they learn from past experiences in ways that shape their perception and activity. In one of her experiments, Dr. Gagliano demonstrates complex learning processes of the common garden pea, Pisum sativum, by training the pea seedlings to associate fan sounds with light in the same way Pavlov trained his dogs more than a century earlier. This study was the first to demonstrate that plants are "capable of performing associative learning tasks involving memory, anticipation, choice behaviors, and decision-making." 22

Working with a local ecological actor as "a process, a swarm of activity, and a dynamic planetary force" ${ }^{\prime 23}$ has the potential to define novel spatial practices. The following project represents an attempt to work with plant behavior and community; engaging issues of disturbance, fragmentation, and social assembly towards the goal of catalyzing hybrid ecological processes.

Behavioral Landscape (BL) is a project developed with Nicolas Azel that proposes autonomous and behavioral partnership between a robotic agent and urban plant communities in a Pittsburgh vacant lot. In the context of the exploitative subsumption of a neighborhood by exclusionary gentrification, and a land maintenance strategy which strips the lot of its agency, we designed a framework for ecological codetermination between robotic and plant intelligence. The rover uses sensors to gauge environmental conditions and site use to behave in real-time, pushing earth and planting seeds using an open database of plant communities. The database is comprised of climactically appropriate plants resilient to stressors like soil contamination, inundation, and drought. They are classified into social groups, which are used to order them into biodiverse superorganisms with associated robotic behavioral schemas (figure 4). The rover sows the seeds in stages. Its paths are dependent on morphological, habitual, and contextual cues that determine speed, repulsion, and attraction (figure 5). The epistemic framework for robot behavior is inspired to work toward the formation of subjectivity and intelligence through logics theorized by Valentino Braitenberg.

Neuroscientist and cyberneticist Valentino Braitenberg develops a conceptual model for a robot in Vehicles: Experiments in Synthetic Psychology, in which he argues for a "science fiction in the service of science." ${ }^{24}$ He explains a series of vehicles that make use of simple interactions between motors and sensors to produce behaviors like fear, aggression, love, and exploration. The introduction of threshold devices can prompt the emergence of value systems, decision-making, and phenomena that look very much like logic and knowledge. Concerning the issue of memory in a system, often argued fundamental to its capacity to learn and adapt, Braitenberg argues that "there is room for memory 

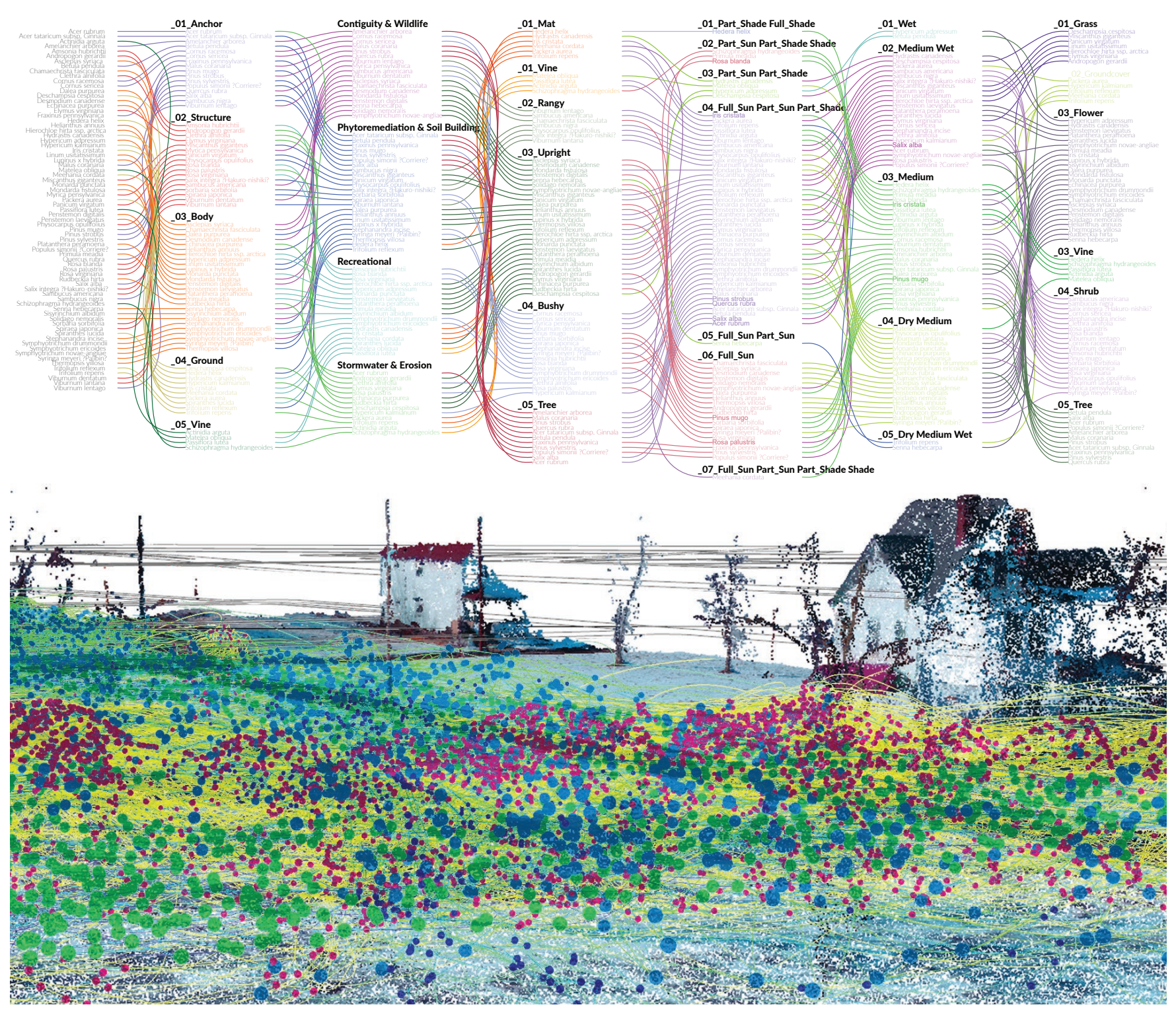

Figure 4. Behavioral Landscape Data and Site. (Photo by author).

in a network of threshold devices, if it is large enough" 25 - i.e. if a light sensor rings a bell when it hits a certain threshold, the ring signifies that the vehicle passed a light, triggering another reaction which does not necessarily need to rely on the memory of passing a light in the way that we traditionally understand memory (as a repository that is called upon). In a situation where a vehicle must, for example, perform a calculation too large for its limited parts, the vehicle can make use of its surroundings to help it. Braitenberg introduces the example of a vehicle on a beach, crawling on the sand, making marks to represent large numbers such that it can crawl back and follow its own track to read the numbers to put back into its calculations. The vehicle is "never able to comprehend these large numbers at any one moment. But using itself as an instrument in a larger scheme involving the environment, and partly directed by it, it ends up with the correct result ${ }^{\prime 26}$. Using its environment enables the vehicle to work on increasingly complex problems.
Such a relationship between agent and environment builds upon an epistemology in which the material and logical boundary between the two begins to blur. BL's rover behavior was designed in this spirit, where the rover builds an intimate relationship with its environment as not its ward, but as its memory and capacity to think. We intend for the codependency coded into our model to put machinic behavior in touch with plant community interactions to create living, dynamic intelligences that translate into complex urban landscapes. Rather than producing, controlling, and navigating data-rich digital environments towards specific performative goals, the intention is for the machine to be data poor, and the environment to be materially, intelligently, and ecologically rich. $B L$ acts as a subjective and material bridge powered by an open-ended epistemological framework that recasts the relationship between mechanical and natural to untether itself from Anthropocentric systems and the human brain. 


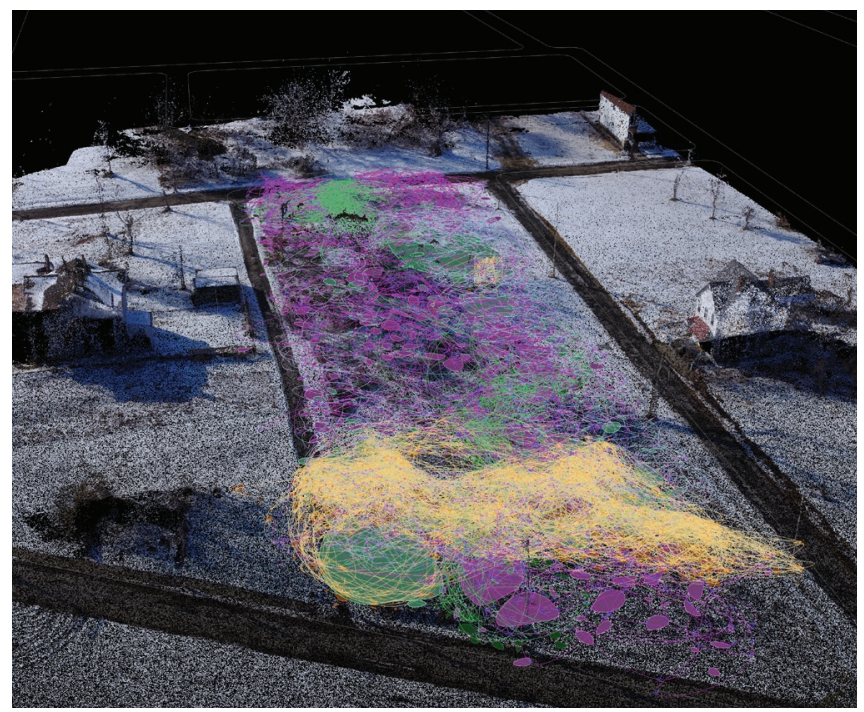

Figure 5. Robotic Schema. (Photo by author).

Working with behavior can be a process of material exploration which describes dynamic vivisections, seeking the expressive capacity of superorganisms to navigate the unexplored affordances of affinity. Decentering the parameterization of environmental exchange recasts the machinations of self-haunting as tangible ecological communications that are able to overcome the blind epistomologies intrinsic to frameworks of control. Trans-species communication, microbial symbiosis, visceral science fictions, the perceptual world of plants, and environmental memory networks can provide insight and inspiration on how to advance an expressive, symbiotic and subjective ecology.

\section{ENDNOTES}

1 Joanna Zylinska, "Minimal Ethics for the Anthropocene," (London: Open Humanities Press, 2014).

2 Timothy Morton, Being Ecological (Cambridge, MA: The MIT Press, 2018), 81.

3 Gilles Deleuze and Félix Guattari, A Thousand Plateaus: Capitalism and Schizophrenia, trans., Massumi (Minneapolis: University of Minnesota Press, 2014).

4 Deleuze and Guattari, 60.

5 Deleuze and Guattari, 61.

6 James Thomson, "City of Dreadful Night," in The City of Dreadful Night and Other Poems (London: Reeves and Turner, 1880).

7 Donna Haraway, The Haraway Reader (New York: Routledge, 2004), 13.

8 Morton, Being Ecological, 90.

9 Deleuze and Guattari, A Thousand Plateaus, 10.

10 Haraway, The Haraway Reader, 7.

11 Maurice Merlau-Ponty, The Visible and the Invisible, trans., Lingis (Evanston: Northwestern University Press, 1968), 123.

12 Lynn Margulis, Origin of Eukaryotic Cells (New Haven, CT: Yale University Press, 1970).

13 Robert E. Cook, "Do Landscapes Learn? Ecology's 'New Paradigm' and Design in Landscape Architecture," in Projective Ecologies, eds., Chris Reed and NinaMarie Lister (New York: ACTAR, Harvard Graduate School of Design, 2014), 222.

14 Herbert Marcuse, One Dimensional Man (Boston: Beacon Press, 1964).

15 Haraway, The Haraway Reader, 16.
16 Timothy Morton, “Architecture Without Nature," in Tarp: Not Nature (2012): 23. https://issuu.com/tarp/docs/notnature_finaldraft_041012.

17 Byung-Chul Han, Transparency Society (Stanford: Stanford University Press, 2015).

18 Skylar Tibbits, Active Matter (Cambridge, MA: The MIT Press, 2017), 16.

19 Robert Macfarlane, "The Secrets of the Wood Wide Web," The New Yorker, August 7, 2016. https://www.newyorker.com/tech/elements/ the-secrets-of-the-wood-wide-web.

20 Katherine Carter Ewel and HT Odum, "Cypress Swamps for Nutrient Removal and Wastewater Recycling," summary of work done by a research group through the University of Florida Center for Wetlands, 1978.

21 Monica Gagliano, "Plant Cognition," https://www.monicagagliano.com/.

22 Monica Gagliano, et al., "Learning by Association in Plants," Scientific Reports 6, 2016

23 Rosetta S. Elkin, "Plant Life: The Practice of 'Working Together,'” in Posthuman (New York: ACTAR, Harvard Graduate School of Design, 2014), 133.

24 Valentino Braitenberg, Vehicles: Experiments in Synthetic Psychology (Cambridge, MA: The MIT Press, 1986), 1.

25 Braitenberg, 24.

26 Braitenberg, 24. 